\title{
Migration Induced by Sea Level Rise could Reshape the U.S. Population Landscape
}

\author{
Mathew E. Hauer \\ Department of Geography \\ University of Georgia \\ hauer@uga.edu
}

\begin{abstract}
Many sea level rise assessments focus on populations presently inhabiting vulnerable coastal communities, but to date no studies have attempted to model the destinations of these potentially displaced persons. With millions of potential future migrants in heavily populated coastal communities, sea level rise scholarship focusing solely on coastal communities characterizes sea level rise as primarily a coastal issue, obscuring the potential impacts in landlocked communities created by sea level rise induced displacement. Here I address this issue by merging projected populations at-risk of sea level rise with migration systems simulations to project future destinations of sea level rise migrants in the United States (U.S.). I find that unmitigated sea level rise is expected to reshape the U.S. population distribution, potentially stressing landlocked areas unprepared to accommodate this wave of coastal migrants - even after accounting for potential adaptation. These results provide the first glimpse of how climate change will reshape future population distributions and establishes a new foundation for modelling potential migration destinations from climate stressors in an era of global environmental change.
\end{abstract}

Keywords: Migration, sea level rise, climate change.

\section{Citation}

Hauer, M.E., 2017. Migration induced by sea-level rise could reshape the US population landscape. Nature Climate Change, 7, pp.321-325. DOI: 10.1038/nclimate3271 


\section{Introduction}

It is generally understood that sea level rise of $1 \mathrm{~m}$ to $2 \mathrm{~m}$ (DeConto and Pollard 2016; Vermeer and Rahmstorf 2009; Levermann et al. 2013) could lead to widespread human migration (IPCC 2014; Strauss, Kulp, and Levermann 2015) as residents of highly vulnerable coastal communities look to escape rising water levels. With up to 180 million people directly at risk to sea level rise in the world and over 1 billion living in the lower elevation coastal zone (Nicholls et al. 2011; Neumann, Vafeidis, et al. 2015), understanding the ramifications of these potential migrants on destination communities is a priority for climate change research (Black, Bennett, et al. 2011; Döös 1997; Mueller, Gray, and Kosec 2014; Hugo 2011a).

Sea level rise assessments, identifying both the number and locations of potentially displaced persons, fill the literature (Strauss, Kulp, and Levermann 2015; Hauer, Evans, and Mishra 2016; Ben and Anders 2014) and are useful for the deployment of critical infrastructure in coastal areas. Yet questions of where the millions of potentially displaced persons will go remain unanswered despite a general understanding that sea level rise displaced persons are likely to have profound effects on future population landscapes (Döös 1997; Ben and Anders 2014). Only a few studies have put forth general hypotheses regarding sea level rise migration (Curtis and Schneider 2011; Döös 1997) and this void has prompted recent calls for additional migration modeling (Willekens et al. 2016; Hugo 2008). To date, no studies modeling precisely how sea level rise induced migration will affect the population distribution exist. By focusing solely on coastal communities without directly addressing sea level rise induced migration, we likely underestimate the scale, magnitude, and geographies of these impacts.

Relationships between environmental stressors and migration are highly complex as press and pulse events trigger migration responses that range from short-distance temporary migration to permanent long-distance migration; some will move and others will not (McLeman 2013a; Gutmann and Field 2010; Collins et al. 2010; Hunter, Murray, and Riosmena 2013; Thiede and Brown 2013; Entwisle et al. 2016). Sea level rise is unique among environmental stressors as the conversion of habitable land to uninhabitable water is expected to lead to widespread human migration without the deployment of costly protective infrastructure 
(Döös 1997; IPCC 2014; Curtis and Schneider 2011; Strauss, Kulp, and Levermann 2015). It is unclear, however, what will actually trigger future climate migrants: press events, such as drought or sea level rise, etc. or pulse events such as tropical cyclones. When climate effects are integrated over long periods of time, it is likely that a combination of press and pulse events will spur migration (Arenstam Gibbons and Nicholls 2006) across preexisting migration pathways (Hunter, Murray, and Riosmena 2013; Gutmann and Field 2010), leveraging established networks of social capital and kin networks in destination decisions (Findlay 2011). This is because press and pulse events that spur migration operate mostly independently of the kin networks and social capital that drive destination decisions (Black, Bennett, et al. 2011). Thus, climate migrants resulting from press stressors will likely constitute "enhanced", or extra, normal out-migration.

I combine estimates of the populations at-risk to sea level rise (Hauer, Evans, and Mishra 2016) within a migration systems simulation to estimate both the number and destinations of potential sea level rise migrants in the United States (U.S.) over the coming century. By focusing on the destinations of sea level rise migrants I am able to more holistically describe the impacts of sea level rise. This study aims to answer one fundamental question regarding sea level rise induced migration: Where will sea level rise migrants likely migrate? Local officials in landlocked communities can use these results to plan for potential infrastructure required to accommodate an influx of coastal migrants and could shift the conceptualization of sea level rise from a coastal issue to an everywhere issue.

\section{Methods and Materials}

I utilize two primary sources of data concerning the magnitude of flows in the migration system and the migration system itself. The first, the magnitude of flows, comes from published populations projected to be at risk to sea level rise (Hauer, Evans, and Mishra 2016). Hauer et al. (Hauer, Evans, and Mishra 2016) used the National Oceanic and Atmospheric Administration's (NOAA) 0m, 0.9m (3 feet), and 1.8m (6 feet) sea level rise datasets for twenty-two coastal states and the District of Columbia. These datasets simulate expected changes in the mean higher high water (MHHW) mark on areas that are hydrologically con- 
nected to coastal areas without taking into account additional land loss caused by other natural factors such as erosion. They projected populations using a modified Hammer Method (Hammer et al. 2004) combined with the Housing Unit Method (Hauer, Evans, and Alexander 2015) for population estimation to create temporally contiguous sub-county boundaries over a 70-year base period from 1940-2010, which were then used to project populations at these same sub-county geographies through the use of a linear/exponential extrapolation approach for projecting Census Block Groups (CBG) from 2010 to 2100. The populations at risk to sea level rise, aggregated to the US County and available in their Supplementary Table 2 (Hauer, Evans, and Mishra 2016), provide the magnitude of out migrants from 319 coastal counties.

For this research, I used the Internal Revenue Service's (IRS), produced in conjunction with the US Census Bureau, annual series of county-to-county migration datasets (IRS 2016) as the basis for the migration system. The IRS datasets utilize the IRS Individual Master File containing every Form 1040, 1040A, and 1040EZ processed by the IRS and includes 95 to 98 percent of all individual tax filers and their dependents. The Census Bureau identifies migrants when a current filing years' return is from a different location than the matched preceding years' return. These data only capture the tax-filing universe but the spatio-temporal stability (Rogers, Little, and Raymer 2010; Engels and Healy 1981; Franklin and Plane 2006) coupled with the very large administrative sample make them attractive for modeling large scale migration patterns. The IRS does suppress migration flows comprising fewer than 10 individual migrants, systemically suppressing small rural migration flows. However the longterm trend of rural out-migration to urban areas (Lichter and Brown 2011) is expected to continue in this century (Jones and O’Neill 2013).

Migration systems theory (MST) has been tied to environmental migration in recent years (DeWaard, Kim, and Raymer 2012; Fawcett 1989; Curtis, Fussell, and DeWaard 2013; Fussell, Curtis, and DeWaard 2014). MST is a branch of migration research that holistically examines migration options by studying all origin-destination combinations rather than any single origin-destination combination (Fawcett 1989; Massey et al. 1994; DeWaard, Kim, and Raymer 2012). Migration decisions - not just the decision to migrate, but also decisions on where to migrate - are often driven by kin networks, employment opportunities, amenities, 


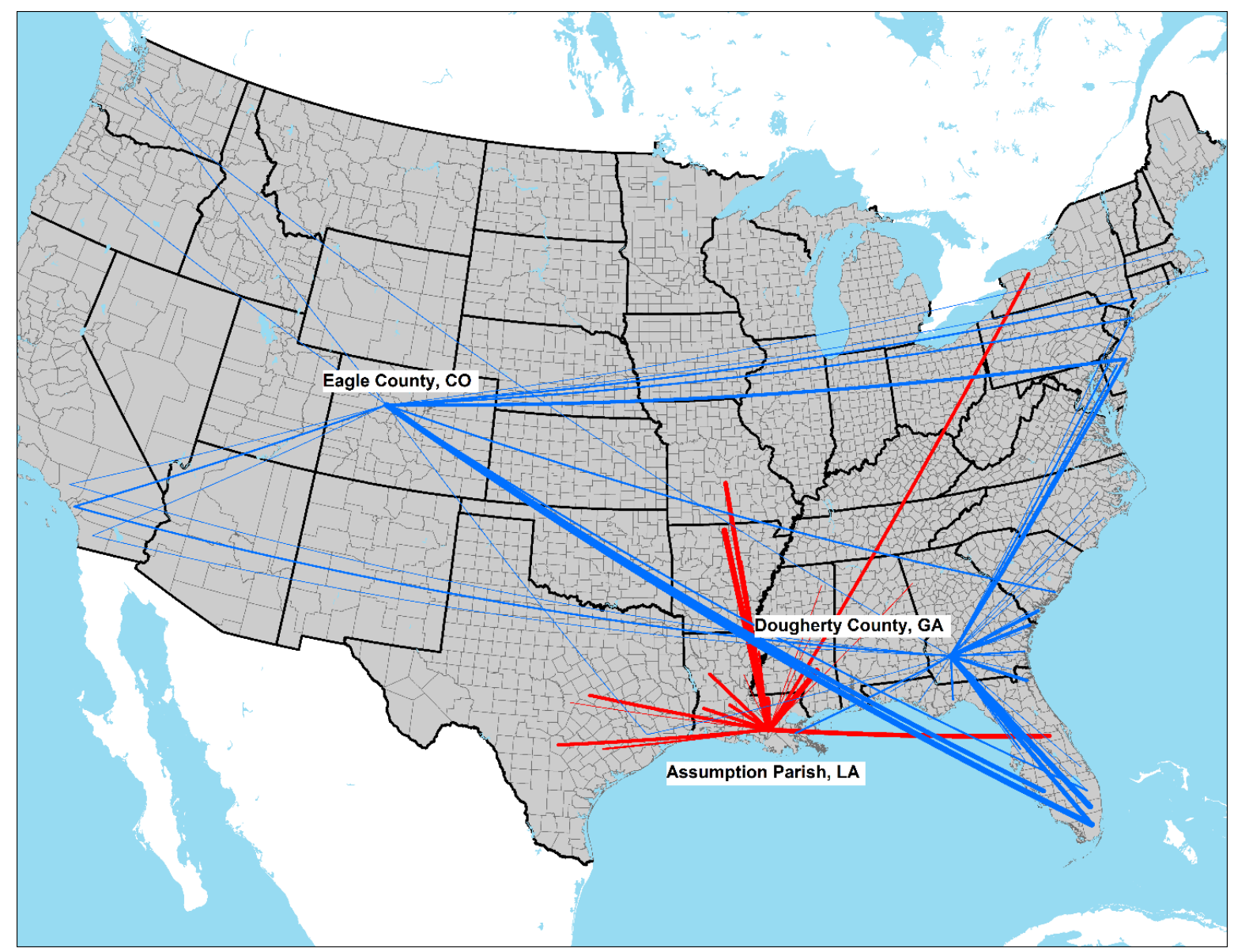

Figure 1: Sample migration systems from the IRS' county-to-county migration dataset for Eagle County Co, Assumption Parish LA, and Dougherty County GA. The thicker the band, the more migrants. Blue bands represent destination systems while red bands represent origin systems.

both natural and economic, economic vitality, and so forth (Lee 1966; Pandit 1997; Fawcett 1989; Haug 2008; Thiede and Brown 2013; Black, Bennett, et al. 2011). This network of "pull" factors embedded within the migration system tends to drive locational decision making due to environmental, or other, "push" factors (Hugo 2008; Hugo 2011b; Schultz and Elliott 2013; Gray and Bilsborrow 2013; McLeman 2013b; Findlay 2011; Black, Bennett, et al. 2011).

To describe the complete migration system in the United States, let matrix $M(x)$ represent all possible county level origin-destination combinations. The sum of any given column and row in the matrix will equal the total number of migrants into or out of any given county. For this analysis I am only concerned with the 319 coastal counties expected to experience 
some form of sea level rise inundation under the $1.8 \mathrm{~m}$ scenario and their connections to the other 3,113 US counties ( $\mathrm{n}=993,047$ matrix cells). I created these matrices for each year of the IRS migration data between 1990 and 2013. Figure 1 shows examples of these systems into and out of three sample counties.

$$
\begin{aligned}
& M(x)=\left\{\begin{array}{ccc}
M_{i, i} & \cdots & M_{i, j} \\
\vdots & \ddots & \vdots \\
M_{j, i} & \cdots & M_{j, j}
\end{array}\right\}=\left[m_{o, d}^{x}\right] \\
& \text { where } \\
& o \in 1, \ldots, 319 \\
& d \in 1, \ldots, 3113
\end{aligned}
$$

I employed the use of an unobserved components model (UCM) for forecasting equally spaced univariate time series data (Harvey 1990). UCMs decompose a time series into components such as trends, seasons, cycles, and regression effects and are designed to capture the features of the series that explain and predict its behavior. UCMs are similar to dynamic models in Bayesian time series forecasting (Harrison and West 1999). All projections were undertaken in SAS 9.4 using the PROC UCM procedure.

The basic structural model (BSM) is the sum of its stochastic components. Here I use a trend component $\mu_{t}$ and a random error component $\varepsilon_{t}$ and it can be described as:

$$
y_{t}=\mu_{t}+\varepsilon_{t}
$$

Each of the model components are modeled separately with the random error $\varepsilon_{t}$ modeled as a sequence of independent, identically distributed zero-mean Gaussian random variables. The trend component is modeled using the following equations: 


$$
\begin{array}{r}
\mu_{t}=\mu_{t-1}+\beta_{t-1}+\eta_{t} \\
\beta_{t}=\beta_{t-1}+\xi_{t} \\
\eta_{t} \sim N\left(0, \sigma_{\eta}^{2}\right) \\
\xi_{t} \sim N\left(0, \sigma_{\xi}^{2}\right)
\end{array}
$$

These equations specify a trend where the level $\mu_{t}$ and the slope $\beta_{t}$ vary over time, governed by the variance of the disturbance terms $\eta_{t}$ and $\xi_{t}$ in their equations. Here all origin-destination dyadic pairs containing any migration information over the series were modelled $(\mathrm{n}=46,203)$ in individual UCM models.

This approach allows for the projected evolution of the migration system as dyadic pairs either strengthen or weaken over time allowing for migration links to wax or wane over the projection horizon. Empirical simulations of environmental migration have proven very fruitful in the modeling of climate induced migration (Reuveny and Moore 2009; Curtis and Schneider 2011; Feng, Krueger, and Oppenheimer 2010) and here I build upon those efforts by projecting future climate migration.

Our current understanding of the migratory response to sea level rise is still underdeveloped. Will displaced coastal populations relocate into the parts of coastal communities unaffected by sea level rise? Or will displaced persons migrate to more inland areas free from the challenges of sea level rise (Döös 1997; Curtis and Schneider 2011)? Many areas in threatened coastal communities are still eligible for human settlement and could be possible destinations for future sea level rise migrants. To capture both possibilities, I employ a raking procedure to proportionally adjust in-migrants based on the inverse of the proportion of the population affected by sea level rise and a redistribution of those migrants to unaffected counties.

$$
\hat{M}_{o d}^{t}=M_{o d}^{t} \cdot\left(1-D_{d}^{t} / P_{d}^{t}\right)
$$


The adjusted number of in-migrants $M$ to destination county $d$ from origin county $o$ at time $t$ is equal to the number of migrants multiplied by one minus the proportion of the population impacted by sea level rise in the destination county at time $t$. For inland counties, the right side of the equation equals one, yielding no adjustment.

$$
\hat{M}_{o d[i=U]}^{t}=\left(\sum M_{o}^{t}-\sum \hat{M}_{o}^{t}\right) \cdot\left(\frac{\hat{M}_{o d[i=U]}^{t}}{\sum \hat{M}_{o[i=U]}^{t}}\right)
$$

However, the out-migrants from each affected coastal county must be raked to equal the total population at-risk to sea level rise expected to be displaced. This is accomplished by redistributing the difference of the unadjusted migrants $M_{o}^{t}$ from origin $o$ from the adjusted migrants from origin $o$ and multiplying it by the proportion of adjusted migrants from origin $o$ to destination $d$ to the unaffected counties $(i=U)$ from the total adjusted migrants from origin $o$. In this way, the underlying migration system from each individual origin is preserved in the raking procedure.

It is likely that many communities will deploy a wide variety of adaptation measures including sea walls, beach and marsh nourishment, pumps, or elevate homes and roads to protect both people and property and IPCC reports have increasingly emphasized adaptation when discussing sea level rise (Brown et al. 2014). Global estimates of adaptive infrastructure for sea level rise could reach US $\$ 421$ billion (2014 values) per year (Nicholls et al. 2011) and could cost upwards of US\$1.1 trillion in the U.S. (Neumann, Emanuel, et al. 2015). However, the deployment of adaptation measures is driven by wealth for both cities (Georgeson et al. 2016) and individuals (Black, Bennett, et al. 2011; Adger, Arnell, and Tompkins 2005). To approximate this dynamic, I assume that households earning greater than US $\$ 100,000$ per year in the 2011-2015 American Community Survey are likely to adapt to sea level rise in some manner and thus unlikely to migrate. This income threshold represents approximately the top quartile and double the U.S. median household income and is neither too restrictive nor too broad to capture the range of individual adaptive measures. 


\subsection{Evaluation of Migration System Projection}

\section{Table 1: Number of IRS migration counts that fall within the $2 / 3$ projection}

interval. This table contains the percentage of dyadic origin-destination pairs where the projected migration flows fall within the $2 / 3$ projection interval.

\begin{tabular}{rrrr} 
Year & $\begin{array}{r}\text { \# within the } 2 / 3 \\
\text { Projection Interval }\end{array}$ & $\begin{array}{r}\text { \# of Dyadic } \\
\text { Migration Pairs }\end{array}$ & \\
\hline 2004 & 34,719 & 46,203 & $75.1 \%$ \\
2005 & 32,391 & 46,203 & $70.1 \%$ \\
2006 & 33,458 & 46,203 & $72.4 \%$ \\
2007 & 33,566 & 46,203 & $72.6 \%$ \\
2008 & 33,960 & 46,203 & $73.5 \%$ \\
2009 & 34,828 & 46,203 & $75.4 \%$ \\
2010 & 34,530 & 46,203 & $74.7 \%$ \\
2011 & 32,217 & 46,203 & $69.7 \%$ \\
2012 & 31,836 & 46,203 & $68.9 \%$ \\
2013 & 33,075 & 46,203 & $71.6 \%$ \\
\hline TOTAL & 334,580 & 462,030 & $72.4 \%$ \\
\hline
\end{tabular}

Projection intervals allow us to examine the feasibility of the future projected migration systems and are typically employed in the evaluation of population projections (Gerland et al. 2014). Population geographers have typically used the $2 / 3$ or $66 \%$ projection interval to assess the accuracy of a population projection (Tayman, Smith, and Lin 2007; Swanson and Beck 1994), representing "low" and "high" scenarios that are "neither so wide as to be meaningless nor too narrow to be overly-restrictive." (Swanson and Tayman 2015).

To examine the feasibility of the migration system projections, I produce projections based on the equations in the preceding section with the base period 1990-2003 and an evaluation period of 2004-2013. If less than $2 / 3$ of the IRS migration counts fall within the $2 / 3$ 
projection interval then the results would suggest less than ideal accuracy. However, if more than $2 / 3$ of the IRS migration counts fall within the $2 / 3$ projection interval, it would suggest an ideal amount of accuracy. I assessed the $2 / 3$ interval for 10 years of projections for an evaluation of base period 1990-2003 and a projection period of 2004-2013.

Table 1 shows the overall number of IRS migration counts that fall within the $2 / 3$ projection interval for each year of the evaluation period. Overall, the UCMs produce robust projections as all projection years are above the $2 / 3$ projection interval.

\section{Results}

I find that in the U.S., every state, $86 \%$ of U.S. Core Based Statistical Areas (CBSA) (791 out of 915 ), and $56 \%$ of counties $(1,735$ out of 3,113$)$ could be affected in some way by net migration (in-migration minus out-migration) associated with $1.8 \mathrm{~m}$ of sea level rise (Figure 4). Florida could lose more than 2.5 million residents due to $1.8 \mathrm{~m}$ of sea level rise while Texas could see nearly 1.5 million additional residents (Figure 3). Additionally, nine states could see net-losses in their populations due to sea level rise. Figure 2 demonstrates all origin-destination flows at the U.S. state level demonstrating that the sheer magnitude of places affected could alter the U.S. population landscape. sea level rise migrants are expected to comprise both intra- and inter-state migrations and no state is left untouched by sea level rise migration. Even accounting for the deployment of adaptive infrastructure, millions of people could still migrate (Table 2).

My results also suggest that CBSAs such as Austin TX, Orlando FL, Atlanta GA, and Houston TX could see more than 250,000 previously unforeseen future sea level rise net migrants each (Table 2). Thirteen CBSAs could see more than 100,000 sea level rise net migrants by 2100 with $1.8 \mathrm{~m}$ of sea level rise. Conversely, ten CBSAs could lose more than 100,000 residents due to sea level rise with Miami FL losing over 2.5 million residents. Even accounting for those who could adapt in place, many inland communities could see tens of thousands of sea level rise in migrants and many coastal communities could lose tens 


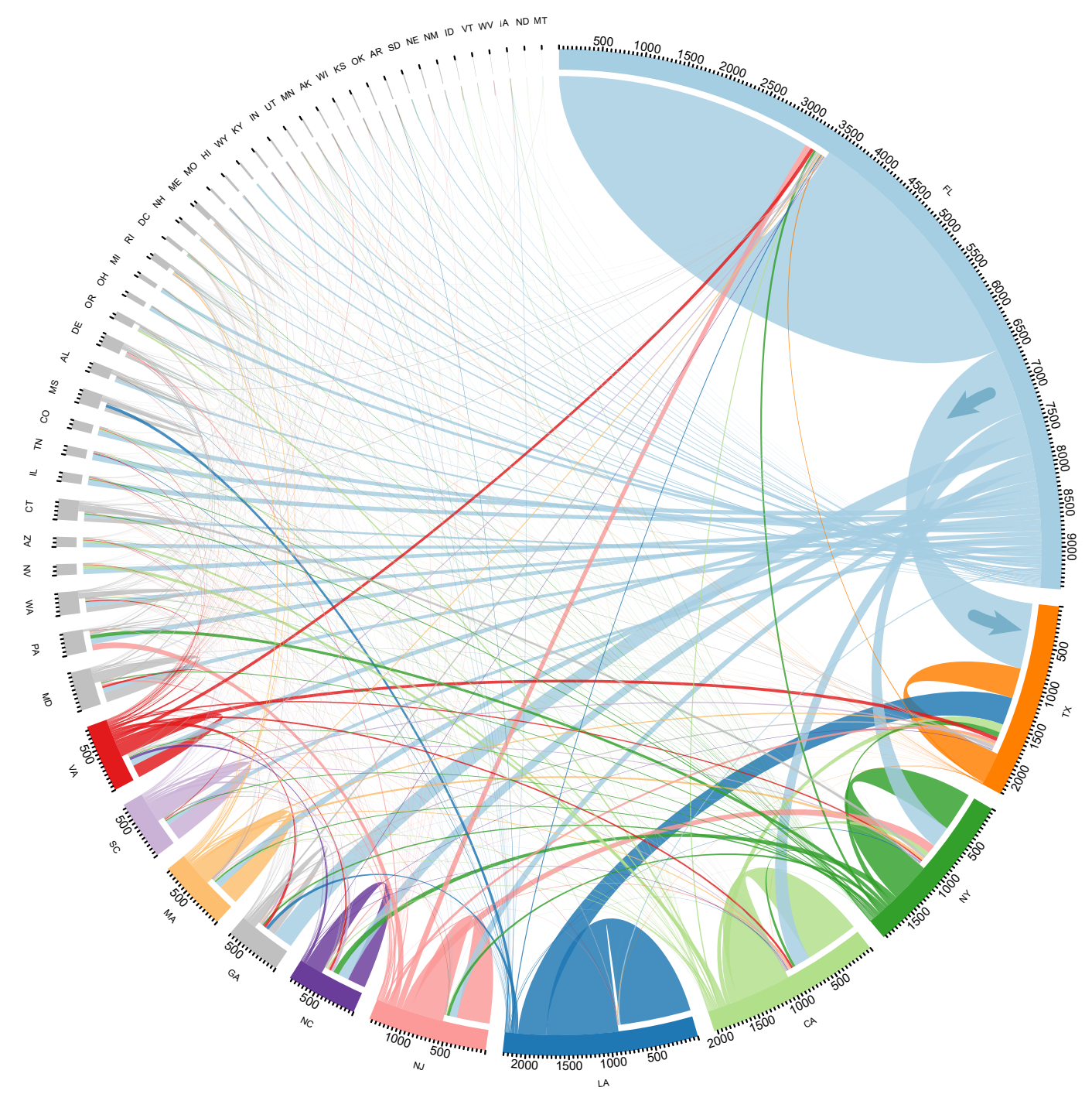

Figure 2: Circular plot of bi-lateral sea level rise migration flows for US States under the $1.8 \mathrm{~m}$ scenario and no adaptation. Tick marks show the number of migrants (inflows and outflows) in thousands. States are ordered clockwise by the size of inflows. 
Table 2: Select core based statistical area (CBSA) destinations of sea level rise net migration (in-migration minus out-migration) in 2100 with and without adaptation under the $1.8 \mathrm{~m}$ scenario. +/- represents the 80th confidence interval.

CBSA

Austin-Round Rock, TX

Orlando-Kissimmee-Sanford, FL

Atlanta-Sandy Springs-Roswell, GA

Phoenix-Mesa-Scottsdale, AZ

Myrtle Beach-Conway-N Myrtle Beach, SC-NC

North Port-Sarasota-Bradenton, FL

Los Angeles-Long Beach-Anaheim, CA

New York-Newark-Jersey City, NY-NJ-PA

New Orleans-Metairie, LA

Miami-Fort Lauderdale-West Palm Beach, FL

\begin{tabular}{|rr|}
\multicolumn{3}{c}{ No Adaptation } \\
\begin{tabular}{|rr} 
Net-Migration & $+/-$ \\
818,938 & 243,821 \\
461,411 & 62,665 \\
320,937 & 131,984 \\
100,524 & 12,851 \\
12,146 & 13,855 \\
-208 & 25,057 \\
$-3,140$ & 51,590 \\
$-50,804$ & 494,625 \\
$-500,011$ & 24,053 \\
$-2,509,978$ & 155,119
\end{tabular}
\end{tabular}

With Adaptation

\begin{tabular}{|c|c|c|c|}
\hline & WItn AC & aptatior & \\
\hline Rank & Net-Migration & $+/-$ & Rank \\
\hline 1 & 625,627 & 179,186 & 1 \\
\hline 2 & 369,120 & 38,834 & 2 \\
\hline 3 & 248,684 & 68,868 & 3 \\
\hline 13 & 73,935 & 1,949 & 13 \\
\hline 78 & 3,142 & 9,389 & 141 \\
\hline 727 & 2,128 & 21,717 & 168 \\
\hline 737 & 13,181 & 22,200 & 61 \\
\hline 775 & 15,808 & 194,047 & 50 \\
\hline 795 & $-373,283$ & 10,733 & 795 \\
\hline 796 & $-2,009,263$ & 95,845 & 796 \\
\hline
\end{tabular}

of thousands of residents. Extended results for all counties and CBSAs are available in the supplementary materials (Supplementary Dataset).

With many projected migrants remaining in coastal communities (Table 2 and Supplementary Dataset), sea level rise could generate millions of "trapped" people (Black et al. 2013). Trapped populations are sometimes discussed through the concept of involuntary immobility (Black et al. 2013), but there is also those who do not desire to move and thus constitute voluntary immobility. These results suggest that many people displaced by sea level rise could find themselves or their descendants exposed to sea level rise, even with migration as an adaptation, as sea levels continue to rise past the year 2100 and migration that constitutes relocation to presently safe, but ultimately vulnerable, coastal communities.

Additionally, infrastructure challenges required to protect coastal communities are well documented (Hauer, Evans, and Mishra 2016; Strauss, Kulp, and Levermann 2015), but the infrastructure challenges of accommodating millions of sea level rise migrants in largely unprepared inland municipalities is virtually unexplored. For many destinations, such as Riverside CA, Phoenix AZ, Las Vegas NV, and Atlanta GA, already experiencing water management and growth management challenges, the sea level rise migrants who wash across the landscape over the coming century could place undue burden in these places if accommodation strategies are left unplanned. Studies of migration impacts do not solve the challenges in these areas, but rather reveal a more holistic understanding of sea level rise impacts and needed interventions. 


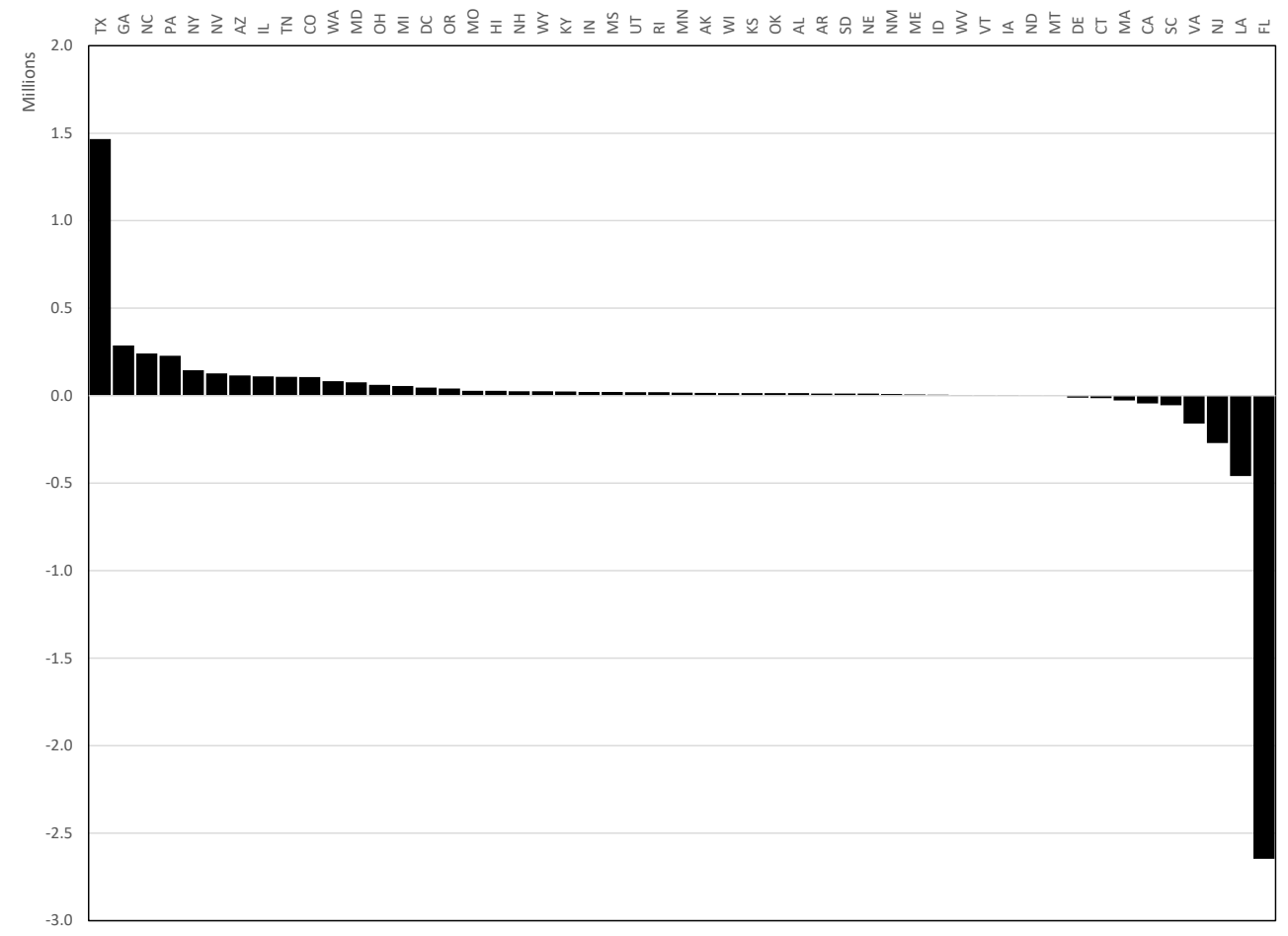

Figure 3: Net change in population due to sea level rise under the $\mathbf{1 . 8 m}$ scenario and no adaptation. I considered migration destinations for all 50 states and the District of Columbia and migration origins for 22 states and the District of Columbia. These are the net changes in population due to both in- and out-migration due to sea level rise. 

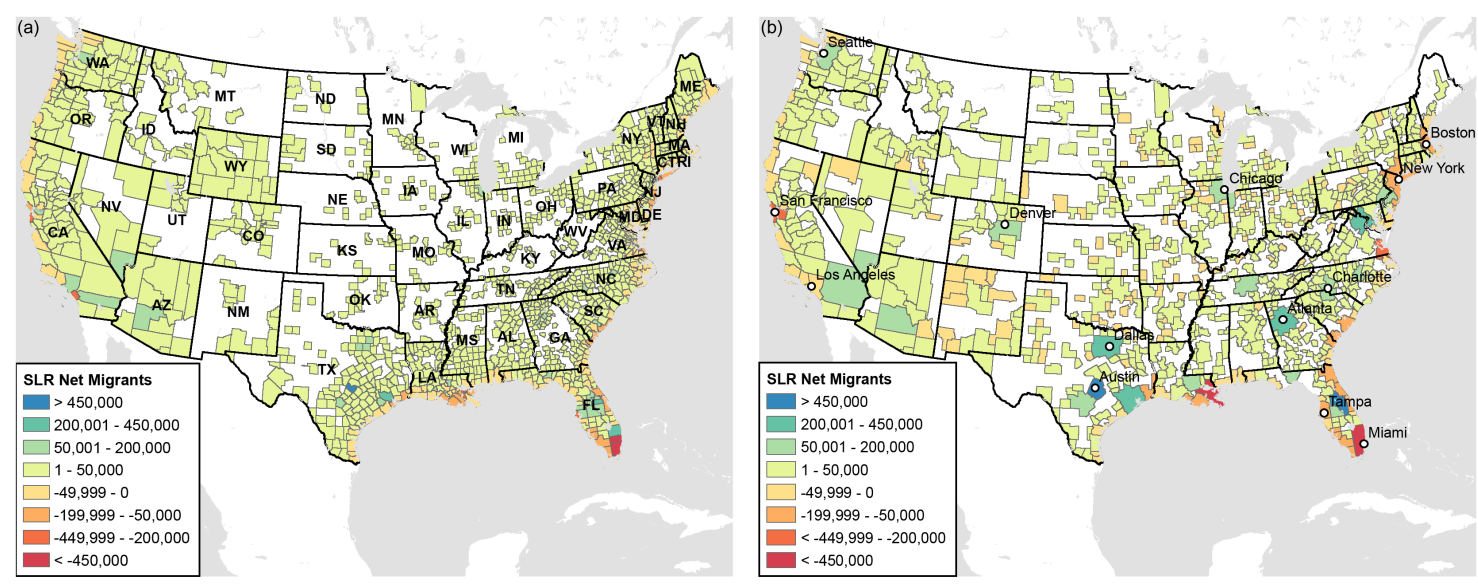

Figure 4: Estimated sea level rise net migrants (in-migrants minus out-migrants) for counties (a) and core based statistical areas (b) under the $1.8 \mathrm{~m}$ scenario and no adaptation. I considered migration destinations for all 50 states and the District of Columbia and migration origins for 22 states and the District of Columbia. These are the net changes in population due to both in- and out-migration due to sea level rise.

\section{Discussion}

sea level rise has been broadly conceptualized as a coastal issue or hazard, as assessments have focused on the effects in coastal communities (Strauss, Kulp, and Levermann 2015; Hauer, Evans, and Mishra 2016; Neumann, Vafeidis, et al. 2015; Nicholls et al. 2011). With millions of potential future migrants in heavily populated coastal communities, sea level rise scholarship focusing solely on coastal communities endorses a narrative that characterizes sea level rise as primarily a coastal issue, obscuring the potential impacts in landlocked communities created by sea level rise driven migration. My work shows that this coastal conceptualization of sea level rise creates a deceptively small area of affect if relocation is left unaccounted. This work offers the first glimpse of how sea level rise could alter the population distribution of the U.S. as both coastal and landlocked communities are likely to be affected by sea level rise: directly in coastal areas due to sea level rise itself and indirectly in landlocked areas through the influx of people escaping sea level rise.

Furthermore, the migration approach for examining destinations associated with climate change shown here allows for modeling migration destinations of other climate change 
stressors. For instance, it has been estimated that parts of the Middle East and North Africa (MENA) could become uninhabitable by the end of the century, potentially spurring an exodus of 500 million people (Lelieveld et al. 2016). Future scholars could employ my approach to model the destinations of these potential MENA migrants. There is tremendous potential in coupling migration systems information with climate change models to examine the implications of climate change induced migration. This type of modeling requires detailed origin-destination migration information, limiting the areas where this approach could be used to those where data are available.

Migration models are only as good as the data underlying them. The suppression of IRS migration data of flows with fewer than 10 migrants could systematically bias my results against rural areas far from coastal communities and the modeling approach undertaken does not allow for new unforeseen migration pairs to emerge in the future. However, the destination counties cover $93.6 \%$ of the U.S. population and over 250 destination counties are outside of CBSAs (the typical distinction of urban/rural), limiting the scope of the rural bias to mainly sparsely populated communities far from coastal areas. New destinations for sea level rise migrants could still emerge in rural areas, and if they do, my results of the geographic spread of sea level rise migrants could be considered conservative. Environmental migration scholars could further investigate the likelihood of emerging rural destinations related to climate change migration to better inform future modeling efforts.

Previous trends are not always indicative of future results. Societal and economic shifts, population ceilings, local growth ordinances, adaptive behavior, and climate change itself could all change future migrant destinations. Although I model the potential destinations of sea level rise migrants, I do not precisely model how other climate stressors or other factors might influence the future migration systems. Our current understanding of the location decisions of environmental migrants is still limited and there have been recent calls to better understand migration flows (Willekens et al. 2016). My approach builds on the growing literature concerning migrant destinations and environmental change (Findlay 2011; Smith et al. 2011; Black, Kniveton, and Schmidt-Verkerk 2011; Black, Bennett, et al. 2011; Black, 
Adger, et al. 2011; Curtis and Schneider 2011; Döös 1997) and accounts for potential future migration systems.

High potential exists for development of deeper and more integrated examinations of the role of adaptation and other climate stressors on SLR migration. Neglecting to account for adaptive behavior could lead to an overestimation of either flood risk (Haer et al. 2016) or migration (Kocornik-Mina et al. 2016). Future studies could examine varying adaptation scenarios related to the 100 -year flood plain or the lower-elevation coastal zone creating differing scenarios of "stayers."

If future migration pathways mimic past pathways, sea level rise is expected to reshape the U.S. population distribution and could stress some landlocked areas unprepared for these migrations while revitalizing others. sea level rise is currently framed as a coastal hazard but the migratory effects could ripple far inland. My results show the importance of accounting for future migrations associated with climate change in long range planning processes for disaster management, transportation infrastructure, land use decisions, etc..

\section{Data Availability}

The data that support the findings of this study have been deposited in openICPSR (10.3886/E100413V3). 


\section{References}

Adger, W. N., N. W. Arnell, and E. L. Tompkins. 2005. Successful adaptation to climate change across scales. Global Environmental Change 15 (2):77-86.

Arenstam Gibbons, S. J., and R. J. Nicholls. 2006. Island abandonment and sea-level

rise: An historical analog from the Chesapeake Bay, USA. Global Environmental Change 16 (1):40-47.

Ben, M., and L. Anders. 2014. Loss of cultural world heritage and currently inhabited places to sea-level rise. Environmental Research Letters 9 (3):034001.

Black, R., W. N. Adger, N. W. Arnell, S. Dercon, A. Geddes, and D. S. G. Thomas. 2011. The effect of environmental change on human migration. Global Environmental ChangeHuman and Policy Dimensions 21:S3-S11.

Black, R., N. W. Arnell, W. N. Adger, D. Thomas, and A. Geddes. 2013. Migration, immobility and displacement outcomes following extreme events. Environmental Science $\mathfrak{E}$ Policy 27:S32-S43.

Black, R., S. R. G. Bennett, S. M. Thomas, and J. R. Beddington. 2011. Migration as adaptation. Nature 478 (7370):447-449.

Black, R., D. Kniveton, and K. Schmidt-Verkerk. 2011. Migration and climate change: towards an integrated assessment of sensitivity. Environment and Planning A 43 (2):431-450.

Brown, S., R. J. Nicholls, S. Hanson, G. Brundrit, J. A. Dearing, M. E. Dickson, S. L. Gallop, S. Gao, I. D. Haigh, J. Hinkel, J. A. Jimenez, R. J. T. Klein, W. Kron, A. N. Lazar, C. F. Neves, A. Newton, C. Pattiaratachi, A. Payo, K. Pye, A. Sanchez-Arcilla, M. Siddall, A. Shareef, E. L. Tompkins, A. T. Vafeidis, B. van Maanen, P. J. Ward, and C. D. Woodroffe. 2014. Shifting perspectives on coastal impacts and adaptation. Nature Clim. Change $4(9): 752-755$.

Collins, S. L., S. R. Carpenter, S. M. Swinton, D. E. Orenstein, D. L. Childers, T. L. Gragson, N. B. Grimm, J. M. Grove, S. L. Harlan, and J. P. Kaye. 2010. An integrated conceptual framework for long-term social-ecological research. Frontiers in Ecology and the Environment 9 (6):351-357. 
Curtis, K., E. Fussell, and J. DeWaard. 2013. Do Migration systems predict postdistaster migration patterns?: The case of the Gulf of MExico Coastal counties before and after hurricanes katrina and rita. Paper read at Population Association of America, at New Orleans, LA.

Curtis, K., and A. Schneider. 2011. Understanding the demographic implications of climate change: estimates of localized population predictions under future scenarios of sealevel rise. Population and Environment 33:28-54.

DeConto, R. M., and D. Pollard. 2016. Contribution of Antarctica to past and future sea-level rise. Nature 531 (7596):591-597.

DeWaard, J., K. Kim, and J. Raymer. 2012. Migration Systems in Europe: Evidence From Harmonized Flow Data. Demography 49 (4):1307-1333.

Döös, B. R. 1997. Can large-scale environmental migrations be predicted? Global Environmental Change 7 (1):41-61.

Engels, R. A., and M. K. Healy. 1981. Measuring Interstate Migration Flows - an Origin-Destination Network Based on Internal-Revenue Service Records. Environment and Planning A 13 (11):1345-1360.

Entwisle, B., N. E. Williams, A. M. Verdery, R. R. Rindfuss, S. J. Walsh, G. P. Malanson, P. J. Mucha, B. G. Frizzelle, P. M. McDaniel, and X. Yao. 2016. Climate shocks and migration: an agent-based modeling approach. Population and Environment:1-25.

Fawcett, J. T. 1989. Networks, Linkages, and Migration Systems. International Migration Review 23 (3):671-680.

Feng, S. Z., A. B. Krueger, and M. Oppenheimer. 2010. Linkages among climate change, crop yields and Mexico-US cross-border migration. Proceedings of the National Academy of Sciences of the United States of America 107 (32):14257-14262.

Findlay, A. M. 2011. Migrant destinations in an era of environmental change. Global Environmental Change-Human and Policy Dimensions 21:S50-S58. 
Franklin, R. S., and D. A. Plane. 2006. Pandora's box: The potential and peril of migration data from the American Community Survey. International Regional Science Review 29 (3):231-246.

Fussell, E., K. J. Curtis, and J. DeWaard. 2014. Recovery migration to the City of New Orleans after Hurricane Katrina: a migration systems approach. Population and Environment 35 (3):305-322.

Georgeson, L., M. Maslin, M. Poessinouw, and S. Howard. 2016. Adaptation responses to climate change differ between global megacities. Nature Climate Change 6 (6):584-588.

Gerland, P., A. E. Raftery, H. Ševčíková, N. Li, D. Gu, T. Spoorenberg, L. Alkema, B. K. Fosdick, J. Chunn, N. Lalic, G. Bay, T. Buettner, G. K. Heilig, and J. Wilmoth. 2014. World population stabilization unlikely this century. science.

Gray, C., and R. Bilsborrow. 2013. Environmental influences on human migration in rural ecuador. Demography 50 (4):1217-41.

Gutmann, M. P., and V. Field. 2010. Katrina in historical context: environment and migration in the US. Population and Environment 31 (1-3):3-19.

Haer, T., W. J. W. Botzen, H. de Moel, and J. C. J. H. Aerts. 2016. Integrating Household Risk Mitigation Behavior in Flood Risk Analysis: An Agent-Based Model Approach. Risk Analysis:n/a-n/a.

Hammer, R. B., S. I. Stewart, R. L. Winkler, V. C. Radeloff, and P. R. Voss. 2004. Characterizing dynamic spatial and temporal residential density patterns from 1940â ĂŞ1990 across the North Central United States. Landscape and Urban Planning 69 (2):183-199.

Harrison, J., and M. West. 1999. Bayesian Forecasting \& Dynamic Models: Springer.

Harvey, A. C. 1990. Forecasting, Structural Time Series Models and the Kalman Filter: Cambridge University Press.

Hauer, M., J. Evans, and C. Alexander. 2015. Sea-level rise and sub-county population projections in coastal Georgia. Population and Environment:1-19.

Hauer, M. E., J. M. Evans, and D. R. Mishra. 2016. Millions projected to be at risk from sea-level rise in the continental United States. Nature Climate Change. 
Haug, S. 2008. Migration networks and migration decision-making. Journal of Ethnic and Migration Studies 34 (4):585-605.

Hugo, G. 2008. Migration, development and environment: International Organization for Migration Geneva.

Hugo, G. 2011a. Future demographic change and its interactions with migration and climate change. Global Environmental Change 215:521-533.

Hugo, G. 2011b. Future demographic change and its interactions with migration and climate change. Global Environmental Change-Human and Policy Dimensions 21:S21-S33.

Hunter, L. M., S. Murray, and F. Riosmena. 2013. Rainfall Patterns and U.S. Migration from Rural Mexico. International Migration Review 47 (4):874-909.

IPCC. 2014. Climate Change 2014: Impacts, Adaptation, and Vulnerability. Part A: Global and Sectoral Aspects. Contribution of Working Group II to the Fifth Assessment Report of the Intergovernmental Panel on Climate Change [Field, C.B., V.R. Barros, D.J. Dokken, K.J. Mach, M.D. Mastrandrea, T.E. Bilir, M. Chatterjee, K.L. Ebi, Y.O. Estrada, R.C. Genova, B. Girma, E.S. Kissel, A.N. Levy, S. MacCracken, P.R. Mastrandrea, and L.L. White (eds.)]. Cambridge, United Kingdom and New York, NY, USA: Cambridge University Press.

IRS. SOI Tax Stats - County-to-County Migration Data Files 2016 [cited. Available from https://www.irs.gov/uac/soi-tax-stats-county-to-county-migration-data-files.

Jones, B., and B. C. O’Neill. 2013. Historically grounded spatial population projections for the continental United States. Environmental Research Letters 8 (4).

Kocornik-Mina, A., T. K. McDermott, G. Michaels, and F. Rauch. 2016. Flooded Cities: Centre for Economic Performance, LSE.

Lee, E. S. 1966. Theory of Migration. Demography 3 (1):47-57.

Lelieveld, J., Y. Proestos, P. Hadjinicolaou, M. Tanarhte, E. Tyrlis, and G. Zittis. 2016. Strongly increasing heat extremes in the Middle East and North Africa (MENA) in the 21st century. Climatic Change 137 (1):245-260. 
Levermann, A., P. U. Clark, B. Marzeion, G. A. Milne, D. Pollard, V. Radic, and A. Robinson. 2013. The multimillennial sea-level commitment of global warming. Proceedings of the National Academy of Sciences 110 (34):13745-13750.

Lichter, D. T., and D. L. Brown. 2011. Rural America in an urban society: Changing spatial and social boundaries. Annual Review of Sociology 37:565-592.

Massey, D. S., J. Arango, G. Hugo, A. Kouaouci, A. Pellegrino, and J. E. Taylor. 1994. An Evaluation of International Migration Theory - the North-American Case. Population and Development Review 20 (4):699-751.

McLeman, R. A. 2013a. Climate and human migration: Past experiences, future challenges. New York: Cambridge University Press.

McLeman, R. A. 2013b. Climate and Human Migration: Past Experiences, Future Challenges.

Mueller, V., C. Gray, and K. Kosec. 2014. Heat stress increases long-term human migration in rural Pakistan. Nature climate change 4 (3):182-185.

Neumann, B., A. T. Vafeidis, J. Zimmermann, and R. J. Nicholls. 2015. Future Coastal Population Growth and Exposure to Sea-Level Rise and Coastal Flooding - A Global Assessment. Plos One 10 (3).

Neumann, J. E., K. Emanuel, S. Ravela, L. Ludwig, P. Kirshen, K. Bosma, and J. Martinich. 2015. Joint effects of storm surge and sea-level rise on US Coasts: new economic estimates of impacts, adaptation, and benefits of mitigation policy. Climatic Change 129 (1):337-349 .

Nicholls, R. J., N. Marinova, J. A. Lowe, S. Brown, P. Vellinga, D. de Gusmão, J. Hinkel, and R. S. J. Tol. 2011. Sea-level rise and its possible impacts given a 'beyond $4^{\circ} \mathrm{C}$ world' in the twenty-first century. Philosophical Transactions of the Royal Society A: Mathematical, Physical and Engineering Sciences 369 (1934):161-181.

Pandit, K. 1997. Cohort and Period Effects in US Migration: How Demographic and Economic Cycles Influence the Migration Schedule. Annals of the Association of American Geographers 89:439-450. 
Reuveny, R., and W. H. Moore. 2009. Does Environmental Degradation Influence Migration? Emigration to Developed Countries in the Late 1980s and 1990s*. Social science quarterly 90 (3):461-479.

Rogers, A., J. Little, and J. Raymer. 2010. The indirect estimation of migration: Methods for dealing with irregular, inadequate, and missing data: Springer Science \& Business Media.

Schultz, J., and J. R. Elliott. 2013. Natural disasters and local demographic change in the United States. Population and Environment 34 (3):293-312.

Smith, C., D. R. Kniveton, S. Wood, and R. Black. 2011. Climate Change and Migration: A Modelling Approach. African Climate and Climate Change: Physical, Social and Political Perspectives 43:179-201.

Strauss, B. H., S. Kulp, and A. Levermann. 2015. Carbon choices determine US cities committed to futures below sea level. Proceedings of the National Academy of Sciences.

Swanson, D. A., and D. M. Beck. 1994. A new short-term county population projection method. Journal of Economic and Social Measurement 20 (1):25-50.

Swanson, D. A., and J. Tayman. 2015. On the Ratio-Correlation Regression Method of Population Estimation and Its Variants. In Emerging Techniques in Applied Demography, 93-117: Springer.

Tayman, J., S. Smith, and J. Lin. 2007. Precision, bias, and uncertainty for state population forecasts: an exploratory analysis of time series models. Population Research and Policy Review 26 (3):347-369.

Thiede, B., and D. Brown. 2013. Hurricane Katrina: Who Stayed and Why? Population Research and Policy Review 32 (6):803-824.

Vermeer, M., and S. Rahmstorf. 2009. Global sea level linked to global temperature. Proceedings of the National Academy of Sciences 106 (51):21527-21532.

Willekens, F., D. Massey, J. Raymer, and C. Beauchemin. 2016. International migration under the microscope. Science 352 (6288):897-899. 